\title{
Reparação de Tecidos
}

\author{
Amaral FV. ${ }^{1}$ \\ ${ }^{1}$ Belo Horizonte - Brasil. \\ E-mail:Vânia.amaral@labhpardini.com.br
}

Amaral, F.V. 2013. Reparação de Tecidos, p.72. In: Bastos, Francisco Reis. Anais do V Simpósio Internacional de Flebologia [Blucher Medical Proceedings n.1 v.1]. São Paulo: Blucher, 2014 http://dx.doi.org/10.5151/medpro-flebo-SIF_45
O reparo é o processo responsável pela substituição dos tecidos lesados por elementos novos, sadios e ocorre através da proliferação de tecido conjuntivo neoformado, vascularizado (cicatrização) ou por tecido igual ao original (regeneração). A regeneração é o processo responsável pela restituição da integridade anatômica e funcional em alguns tipos de agressão e epitelização das feridas. A cicatrização é a forma mais comum de reparo e pode ocorrer juntamente com a regeneração. A cicatrização pode ser dividida em três fases, que ocorrem de forma consecutiva e sobreposta: fase inflamatória, fase proliferativa e fase de remodelagem. A fase inflamatória dura três a cinco dias a partir da agressão, quando ocorre a ruptura de vasos e extravasamento de plasma e de elementos figurados do sangue, que ocupam o espaço criado pela lesão. Há liberação de vários mediadores químicos e migração de leucócitos. A fase proliferativa dura dias a seis semanas, caracteriza-se pela proliferação de tecido de granulação (neoformação conjuntivo-vascular) e depende de fatores de crescimento. A fase de remodelagem é prolongada, dura seis meses a anos. Nessa fase ocorre a maturação da matriz extracelular, com síntese e deposição de colágeno tipo I, conferindo à cicatriz uma consistência firme e maior resistência.

Palavras-chave: fibrose, reparo de tecidos, cicatrização. 